\title{
ECONOMICS
}

\section{BOUNDED RATIONALITY AND STRATEGIC UNCERTAINTY IN A SIMPLE DOMINANCE SOLVABLE GAME}

by

\author{
Nobuyuki Hanaki \\ Aix-Marseille University \\ France
}

Nicolas Jacquemet University of Lorraine and Paris School of Economics

France

Stéphane Luchini Aix-Marseille University

France

\section{Adam Zylbersztejn \\ Paris School of Economics and \\ University of Paris}

France 


\title{
Bounded rationality and strategic uncertainty in a simple dominance solvable game*
}

\author{
Nobuyuki Hanaki ${ }^{\dagger} \quad$ Nicolas Jacquemet ${ }^{\ddagger} \quad$ Stéphane Luchini ${ }^{\S} \quad$ Adam Zylbersztejn ${ }^{\Uparrow}$
}

February 2013

\begin{abstract}
How much of the failures to achieve Pareto efficient outcome observed in a simple $2 \times 2$ dominance solvable game can be attributed to strategic uncertainty and how much is actually due to individual bounded rationality? We address this question by conducting a set of experiments involving two main treatments: one in which two human subjects interact, and another in which one human subject interacts with a computer program whose behavior is known. By making the behavior of the computer opponent perfectly predictable, the latter treatment eliminates strategic uncertainty. Our results suggest that observed coordination failures can be attributed equally to individual bounded rationality and strategic uncertainty.
\end{abstract}

Keywords: Strategic Uncertainty, Robot, Bounded Rationality, Experiment

JEL Classification: C92, D83.

\section{Introduction}

Consider a simple two-person two-action coordination game shown in Table 1, where $L<S<H$ and $l \leq m<h$. Just one step of elimination of weakly dominated strategy leads to the Pareto

*This project is partly financed by JSPS-ANR bilateral research grant "BECOA". Ivan Ouss provided much efficient research assistance. We thank Guillaume Fréchette, Frédéric Koessler, Rosemarie Nagel and Jason F. Shogren for their comments. Nobuyuki Hanaki and Nicolas Jacquemet gratefully acknowledge the Institut Universitaire de France. Stéphane Luchini thanks the School of Business at the University of Western Australia for hospitality and support.

${ }^{\dagger}$ Aix-Marseille University (Aix-Marseille School of Economics), CNRS \& EHESS. 2 Rue de la Charité. 13002, Marseille, France. nobuyuki.hanaki@univ-amu.fr

${ }^{\ddagger}$ Paris School of Economics and Université de Lorraine (BETA). 13 Place Carnot, C.O. n ${ }^{\circ}$ 26, 54035 Nancy, France. Nicolas.Jacquemet@univ-lorraine.fr.

${ }^{\S}$ Aix-Marseille University (Aix-Marseille School of Economics), CNRS \& EHESS.2 Rue de la Charité. 13002, Marseille, France. stephane.luchini@univ-amu.fr

`Paris School of Economics and University Paris I Panthéon-Sorbonne. Centre d'Economie de la Sorbonne, 106 Bd. de l'Hopital, 75013 Paris, France. adam.zylbersztejn@malix.univ-paris1.fr 
Table 1: A simple two-person two-action dominance solvable coordination game

\begin{tabular}{lcc}
\hline \hline & \multicolumn{2}{c}{ player $\mathrm{B}$} \\
\hline player $\mathrm{A}$ & $l$ & $r$ \\
\hline$L$ & $(\mathrm{~S} ; \mathrm{l})$ & $(\mathrm{S} ; \mathrm{l})$ \\
\hline$R$ & $(\mathrm{~L} ; \mathrm{m})$ & $(\mathrm{H} ; \mathrm{h})$ \\
\hline \hline
\end{tabular}

efficient outcome where player A and B choose $R$ and $r$, respectively. The Pareto efficient outcome may not be achieved, however, if player A doubts whether player B will choose the dominant strategy $r$. As a result, the dominated outcome $\{L, l\}$ is also a Nash equilibrium of the game. Rosenthal (1981) pointed out such a possibility in a sequential version of this game, in which player A moves first, and questioned the plausibility of the sub-game perfect equilibrium concept proposed by Selten (1975).

This type of failure to achieve the Pareto efficient outcome is confirmed experimentally by Beard and Beil (1994), Beard, Beil, and Mataga (2001), Goeree and Holt (2001), and Cooper and Van Huyck (2003), among others, in both simultaneous move and sequential move versions of this game 1 These studies show that the proportion of player As choosing the "secure choice" $L$ ranges from $16 \%$ to $80 \%$ depending on the payoff structure. As might be expected, the likelihood of action $R$ not only increases as a function of the difference in player A's payoffs from $\{R, r\}$ and $\{L, *\}$ (that is, the value of $H$ relative to $S$ ), but also as a function of player B's benefit from attaining $\{R, r\}$ instead of $\{R, l\}$ ( $h$ relative to $m$ ). These observed coordination failures have been interpreted as the result of strategic uncertainty - i.e. uncertainty about others' behavior. Recently, Jacquemet and Zylbersztejn (2012) investigated how repetition-based learning, cheaptalk communications, and access to information about the past actions of the current opponent can mitigate the effect of strategic uncertainty. In addition, Jacquemet and Zylbersztejn (2011) manipulated the payoff structure in order to neutralize the potential effects of social preferences and to investigate whether such preferences are important sources of strategic uncertainty. In all instances, the share of Pareto dominant outcomes remains strikingly low, ranging from $33 \%$ to $72 \%$ of the experimental outcomes ${ }^{2}$

In explaining the failure to achieve the Pareto efficient outcome in these games, the literature focuses on strategic uncertainty without actually seeking to determine how much of this failure is due to the strategic uncertainty faced by player As and how much to their bounded rationality.

\footnotetext{
1 Cooper and Van Huyck $(2003)$ report that, generally, subjects behave differently depending on whether a game is presented to them in extensive or normal form. For this particular game, however, Cooper and Van Huyck (2003) find that subjects behave alike regardless of the way the game is presented (see game 8 in their experiment).

${ }^{2}$ See Table 3 for a summary.
} 
Beard and Beil (1994) mention bounded rationality but disregard it, based on subjects' statements about their understanding of the experiment and on their answers to an anonymous exit survey. Yet the experimental literature on dominance solvable games often suggests that some subjects behave non-strategically (see, for example, Nagel, 1995, Ho, Camerer, and Weigelt, 1998, among others). Polonio and Coricelli (2012) use eye-tracking data and show that some subjects do not even pay attention to the payoffs of their opponent in simple 2 by 2 games. These results contrast sharply with the findings of Costa-Gomes and Crawford (2006) who argue, based on the estimated parameters of a cognitive hierarchy model in two-person dominance solvable games, that subjects who actually demonstrate non-strategic behaviors are very rare, and that such nonstrategic subjects seem to exist only in subjects' minds.

This is the main open question we seek to address here: do subjects actually behave nonstrategically, or is this only a figment of other subjects' imagination? If they do, how much of observed coordination failures is due to individual bounded rationality and how much is due to strategic uncertainty? To address these questions we implement two examples from the class of very simple dominance solvable games described above. In these games, if all subjects are rational own monetary payoff maximizers, strategic uncertainty is arguably the only source of coordination failure. We test whether or not some subjects indeed behave in a boundedly rational fashion, conducting a set of experiments in which human subjects (acting as player As) interact with player Bs in the form of either (a) other human subjects or (b) computer programs. Computer programs in the role of player B are programmed to always choose $r$, and this fact is clearly explained to the subjects. Therefore, subjects interacting with computers do not face any strategic uncertainty, so that, in this environment, the choice of the secure option $(L)$ by a human subject can only stem from individual bounded rationality.

Surprisingly, few studies are designed in this way to separate the effect of individual bounded rationality from uncertainty about others' rationality (or behavior) $3^{3}$ One exception is Fehr and Tyran (2001), who focus on the strategic aspects of "nominal illusion." They consider four-player repeated price setting games, and introduce a negative nominal shock in the middle of the experiment. They find that roughly half of non-immediate adjustment to the new equilibrium after the shock is due to individual bounded rationality and the other half is due to uncertainty about

\footnotetext{
${ }^{3}$ A growing body of literature uses robots to control for subjects' beliefs about the behavior of their opponents. Robots may not follow the equilibrium strategies, however, because the focus of these papers is not on disentangling the effects of strategic uncertainty and bounded rationality. For instance, Cason and Friedman (1997) consider robot players in an experiment on price formation in a simple market institution. They mainly concentrate on robot traders who follow the Baysian Nash Equilibrium strategy (BNE robot) but also introduce a "Revealing Robot" to investigate whether the convergence towards the equilibrium is due to human subjects mimicking the behavior of BNE robots or is their best response to BNE robots. Their results support the latter hypothesis. In other studies, robots are used to replicate the observed behaviors of subjects in the past (e.g., Ivanov, Levin, and Niederle, 2010) or to make some players follow the predetermined distribution of boundedly rational behaviors (e.g., Embrey, Fréchette, and Lehrer, 2012).
} 
Table 2: The experimental games

\begin{tabular}{lcc}
\hline \hline & \multicolumn{2}{c}{ player B } \\
\hline player A & $l$ & $r$ \\
\hline$L$ & $(9.75 ; 3)$ & $(9.75 ; 3)$ \\
\hline$R$ & $(3 ; 4.75)$ & $(10 ; 5)$ \\
\hline \hline
\end{tabular}

(a) Baseline Game

\begin{tabular}{lcc}
\hline \hline & \multicolumn{2}{c}{ player B } \\
\hline player A & $l$ & $r$ \\
\hline$L$ & $(8.5 ; 8.5)$ & $(8.5 ; 8.5)$ \\
\hline$R$ & $(6.5 ; 8.5)$ & $(10 ; 10)$ \\
\hline \hline
\end{tabular}

(b) Egalitarian Game

others' rationality. In Costa-Gomes and Crawford (2006), some subjects play against computer programs applying not only equilibrium strategies, but also boundedly rational strategies such as Level-1 or Level-2, in two-person guessing games. Beside describing the behavior of computer programs to subjects, Costa-Gomes and Crawford (2006) train subjects to be able to identify what the computer will do. In addition, they exclude all subjects who fail to sufficiently comprehend the rules of the experiment (including the behavior of the computer). This dismissal of subjects may explain the absence of "non-strategic" subjects in their data. Finally, Akiyama, Hanaki, and Ishikawa (2012) investigate the magnitude of these two effects in understanding the deviation of price forecasts from the fundamental values in an experimental asset market a la Smith, Suchanek, and Williams (1988). They fail to find a significant effect of uncertainty about others' rationality.

From our robot treatments, we conclude that individual bounded rationality and strategic uncertainty regarding the behavior of player Bs account almost equally for player As' choices of secure option $(L)$. This separation is of similar magnitude to what is found by Fehr and Tyran (2001) in a more complex four-player normal form game. Our results also point to both the need to better understand the reasons behind the non-payoff maximizing choice of those players who observationally happen to be non-strategic, and the need to design institutions which can credibly reassure the players who react to strategic uncertainty.

The rest of the paper is organized as follows: the experimental design is explained in Section 2. Section 3 summarizes the results, and Section 4 concludes.

\section{Experimental design}

We consider the two games presented in Table 2. The Baseline Game (BG) is used as the baseline treatment in Beard and Beil (1994) as well as in Jacquemet and Zylbersztejn (2011, 2012). The Egalitarian Game (EG) was introduced by Jacquemet and Zylbersztejn (2011) with four other games in an attempt to assess the effect of the relative payoff structure on subjects' behavior.

There are two main differences between BG and EG: (a) The saliency of the Pareto dominant 
equilibrium is enhanced in EG as compared to BG: for a given level of strategic uncertainty, the expected payoff of player A from choosing $R$, instead of $L$, is higher in EG than in BG. (b) The payoff difference for player B between $\{R, l\}$ and $\{R, r\}$ is higher in EG than in BG (1.5 in the former versus 0.25 in the latter). Thus, player Bs are more likely to choose $r$ in EG than BG. These features have the following consequences on player As' expected behavior. Because of (a), player As are more likely to choose $R$ even if the degree of strategic uncertainty remains constant between the two games. At the same time, because of (b), the risk that player Bs choose $l$ is potentially reduced in As' eyes, which again makes them more likely to choose $R$.

Note that, in the absence of any strategic uncertainty, rational player As should always choose $R$ in both games; while if any strategic uncertainty exists, the frequencies of $R$ choices can be higher in EG than in BG due to the two considerations above. Using these two games, we aim to investigate $(i)$ the relative effects of individual bounded rationality and strategic uncertainty in each game, and (ii) whether the contributions of these two effects to the observed failure to achieve Pareto efficient outcomes are relatively stable across the two games.

\section{$2.1 \quad$ Treatments}

The two games are implemented using a between-subject design - only one game is played in each experimental session. For each game, we consider two treatments: Human and Robot. The Human treatments rely on the experimental design of Jacquemet and Zylbersztejn (2012). It introduces two major changes to the original design of Beard and Beil (1994). First, the one-shot game is repeated 10 times, thus allowing repetition-based learning. Each occurrence (round) is one-shot in the sense that roles are fixed, pairs are rematched in each round using a perfect stranger, roundrobin procedure 4 take-home earnings are derived from one round, randomly drawn at the end of each experimental session. Second, we elicit both players' decisions in each occurrence (round) of the game. To do so, we break the original sequentiality of the game and ask each player for unconditional choices in each round. At the end of each round, players are informed only about their own payoffs, and not about the action chosen by their opponent. All stakes are expressed in Euros, the show-up fee is 5 Euros.

In the Human treatment, human subjects taking the role of player A are matched with other human subjects taking the role of player B. In the Robot treatment, human subjects taking the role of player A are matched with a computer program taking the role of player B. The computer is preset to always take decision $r$ in the game. Subjects in this treatment are clearly informed both about the behavior of the computer program - "the computer will choose $r$ in every round, with no exception" (bold in the original instruction sheet) - and about the fact that subjects are matched with the computer program. This is the only difference in rules and procedures between Human and Robot treatments.

\footnotetext{
${ }^{4}$ We avoid the end-game effect by providing no information about the exact number of repetitions.
} 
Note that by explicitly informing subjects about what the computer will do, the Robot treatment completely eliminates strategic uncertainty whatever the sources of such uncertainty. Therefore a rational subject in this treatment should always choose the payoff maximizing choice $R$. If a subject (acting as player A) chooses the secure choice $L$ in this treatment, her choice must be due to some form of bounded rationality. In the Human treatment, by contrast, a rational subject may not choose $R$ because of strategic uncertainty. Thus, a decision $L$ in the Human treatment may arise due to both the strategic uncertainty and the bounded rationality of player A. In other words, the difference in $L$ decisions between the two treatments gives us the effect of strategic uncertainty in each game.

\section{$2.2 \quad$ Experimental procedures}

Upon arrival, participants are randomly assigned to their computers and asked to fill in a short personal questionnaire containing basic questions about their age, gender, education, etc. The pre-distributed written set of instructions is then read aloud. Players are informed that they will play a (unrevealed) number of rounds of the same game, each round with a different partner, and that their own role will not change during the experiment. Before starting, subjects are asked to answer a quiz assessing their understanding of the game they are about to play. Once the quiz and any participants' questions are answered, the experiment begins.

The experiment generates observations under four experimental conditions, varying according to the payoff structure (BG or EG) and player A's interaction partner (human in Human treatment or computer in Robot treatment). All conditions are implemented separately, using a betweensubject design: each subject experiences only one of the two games, and interacts either with other subjects or with a robot.

For each payoff matrix, we ran three human sessions (involving 20 subjects: 10 player As interacting with 10 player Bs), and two robot sessions (involving 20 player As interacting with automated player Bs). The data for the Human treatment come from Jacquemet and Zylbersztejn (2011), while all four Robot sessions were carried out in October 2012. All sessions took place in the Laboratoire d'Economie Experimentale de Paris (LEEP) at University Paris 1 PanthéonSorbonne. Of the 198 participants, 96 were males and 102 were females 5 A vast majority of this population (167 subjects) were students with various fields of specialization. Half of the subjects $(53 \%)$ had already taken part in economic experiments run at LEEP. Participants' average age was about 24. Subjects were recruited via an on-line registration interface adapted from ORSEE (Greiner, 2004) and the experiment was computerized through a software developed under REGATE (Zeiliger, 2000). Each session lasted about 45 minutes, with an average payoff of 12 Euros in Human treatments and 15 Euros in Robot treatments. No subject participated in more than one

\footnotetext{
${ }^{5}$ In one Robot session with EG, we had 18 subjects instead of 20, so for Robot there were 40 subjects for BG and 38 subjects for EG. For Human, we have 60 subjects (half of whom are player As) in both games.
} 
Table 3: Overview of results from Jacquemet and Zylbersztejn (2012, 2011)

\begin{tabular}{c||ccc||cc||cc||c}
\multicolumn{1}{l||}{} & \multicolumn{4}{c}{ Payoffs } & \multicolumn{3}{c||}{ Round 1} & \multicolumn{2}{c|}{ Round 1-10 } & No. of \\
Treatment & $\{L, *\}$ & $\{R, l\}$ & $\{R, r\}$ & Freq $(R)$ & Freq $(r)$ & Freq $(R)$ & Freq $(r)$ & sub. \\
\hline \hline Baseline & $(9.75 ; 3.00)$ & $(3.00 ; 4.75)$ & $(10.0 ; 5.0)$ & 0.233 & 0.800 & 0.490 & 0.807 & 60 \\
Communication & $(9.75 ; 3.00)$ & $(3.00 ; 4.75)$ & $(10.0 ; 5.0)$ & 0.500 & 0.800 & 0.593 & 0.800 & 60 \\
Observation & $(9.75 ; 3.00)$ & $(3.00 ; 4.75)$ & $(10.0 ; 5.0)$ & 0.167 & 0.767 & 0.530 & 0.820 & 60 \\
\hline \hline ET1 & $(9.75 ; 5.00)$ & $(5.00 ; 9.75)$ & $(10.0 ; 10.0)$ & 0.467 & 0.633 & 0.457 & 0.727 & 60 \\
ET3 & $(9.75 ; 5.50)$ & $(5.50 ; 8.50)$ & $(10.0 ; 10.0)$ & 0.575 & 0.800 & 0.575 & 0.828 & 80 \\
ET4 & $(8.50 ; 5.50)$ & $(5.50 ; 8.50)$ & $(10.0 ; 10.0)$ & 0.633 & 0.767 & 0.730 & 0.823 & 60 \\
ET2 & $(8.50 ; 8.50)$ & $(6.50 ; 8.50)$ & $(10.0 ; 10.0)$ & 0.540 & 0.840 & 0.776 & 0.936 & 100 \\
BT2 & $(8.50 ; 7.00)$ & $(6.50 ; 7.00)$ & $(10.0 ; 8.5)$ & 0.500 & 0.933 & 0.743 & 0.940 & 60 \\
\hline \hline
\end{tabular}

Note. Freq $(R)$ and Freq $(r)$ represent aggregate frequencies of $R$ choices by player As and $r$ choices by player Bs, respectively. Note that for effect of Learning (Baseline) and Observation can only be observed in rounds 2-10. BG in this paper is the same as Baseline and EG in this paper is the same as ET2.

experimental session.

\section{Results}

\subsection{Summary of previous results}

Before turning to the results of our experimental treatments, we provide in Table 3 a summary of results obtained by Jacquemet and Zylbersztejn (2012, 2011). Jacquemet and Zylbersztejn (2012) consider the same game as the BG in this paper, but introduce two other treatments: Communication and Observation. In the Communication treatment, player Bs could communicate their intended action to their partners, without any commitment, prior to the decision-making stage. In the Observation treatment, player As could observe the frequencies of $r$ decisions in the past for the current opponent before making the decision. Thus, under Observation, player As had more precise information about each opponent than in Baseline. While no signification difference in the overall (for rounds 1-10) frequencies of either $R$ choices or $r$ choices is observed between Baseline and Observation treatments, the frequency of $R$ choice in the first round under Communication is significantly higher than that in the two other treatments ${ }^{6}$ This result suggests that the cheap-talk communication was, at least initially, effective in reducing the effect of strategic uncertainty.

\footnotetext{
${ }^{6}$ Fisher's exact test (two-tailed) rejects the null hypothesis that the observed behaviors of player As in the first round are the same for Baseline vs Communication and Observation vs Communication treatments $(\mathrm{p}$-values $=$ 0.0596 and 0.0127 , respectively), while the same null hypothesis cannot be rejected for the Observation vs Baseline treatment $(\mathrm{p}$-value $=0.748)$.
} 
Jacquemet and Zylbersztejn (2011) consider five different games that manipulate the values of payoffs from Baseline treatment in Jacquemet and Zylbersztejn (2012) by increasing the saliency of payoffs and/or reducing inequality between payoffs in the efficient outcome. They find that player As react to variations in the saliency of their own payoffs, but tend to neglect variations in player Bs' payoffs. Player Bs' behaviors, in turn, are driven neither by aversion to inequality nor by the saliency of payoffs; nevertheless, they vary systematically across games. It is noteworthy that overall frequencies of $r$ choices increase from $80 \%$ in the Baseline game (BG in our paper) to almost $94 \%$ in ET2 (EG in our paper), these two games showing the lowest and the highest overall frequencies of $R$ choices in Jacquemet and Zylbersztejn (2011). Below, we report BG and EG outcomes in more detail.7

\subsection{Benchmark treatments: The open empirical challenge}

Figure 1 provides an overview of individual behavior in our baseline conditions, Human treatment. The two payoff configurations induce differences in both players' behavior. First, player As are more likely to choose $R$ in EG than in BG, as shown on the left-hand side of Figure 1 . Overall, $49.0 \%$ of choices were $R$ in BG whereas $77.0 \%$ were $R$ in EG. This difference in proportion between the two treatments is significant at a $1 \%$ threshold with $p<0.0018$ The two games also appear quite different in terms of repetition-based learning. In both payoff configurations, we do observe an increasing trend in the proportion of $R$ decisions, but it is more pronounced in EG than in BG. In both games, the percentage of $R$ decisions is at its minimum in period 1 . It is at its maximum in period 10 in EG but not in BG, where the proportion of $R$ decisions slightly decreases after period 5.

In Human treatments, the behavior of player As cannot be accurately interpreted without taking into account the behavior of their partners. This behavior is summarized on the right-hand side of Figure 1. Two main conclusions emerge. First, the proportion of $r$ choices by player Bs suggests that their behaviors are, on average, relatively stable across the 10 rounds in both BG and EG. As a result, the observed time-trend in the behavior of player As cannot be related to any timewise variation in player Bs' decisions. It is more likely the result of repetition-based learning about the likelihood of playing $r$ in the population of player Bs. Second, the behavior of player Bs, however, induces quite distinct levels of strategic uncertainty for player As - the likelihood of

\footnotetext{
7 Jacquemet and Zylbersztejn (2011) conducted experiments in Poland (University of Warsaw for ET2 (40 subjects), ET3 (40 subjects) and ET4 (20 subjects)) as well, while, in this paper, we only use data collected in LEEP, Paris, to maintain homogeneity of subjects between Human and Robot treatments.

${ }^{8}$ We test the difference in proportion of decisions $R$ between treatments by carrying out a bootstrap proportion test that accounts for within-subject correlation - i.e. the fact that the same individual takes 10 decisions. The procedure consists of bootstrapping subjects and their corresponding decisions over all ten rounds instead of bootstrapping decisions as independent observations (see, e.g., Jacquemet, Joule, Luchini, and Shogren, 2012 , for a detailed description of the procedure).
} 
Player A
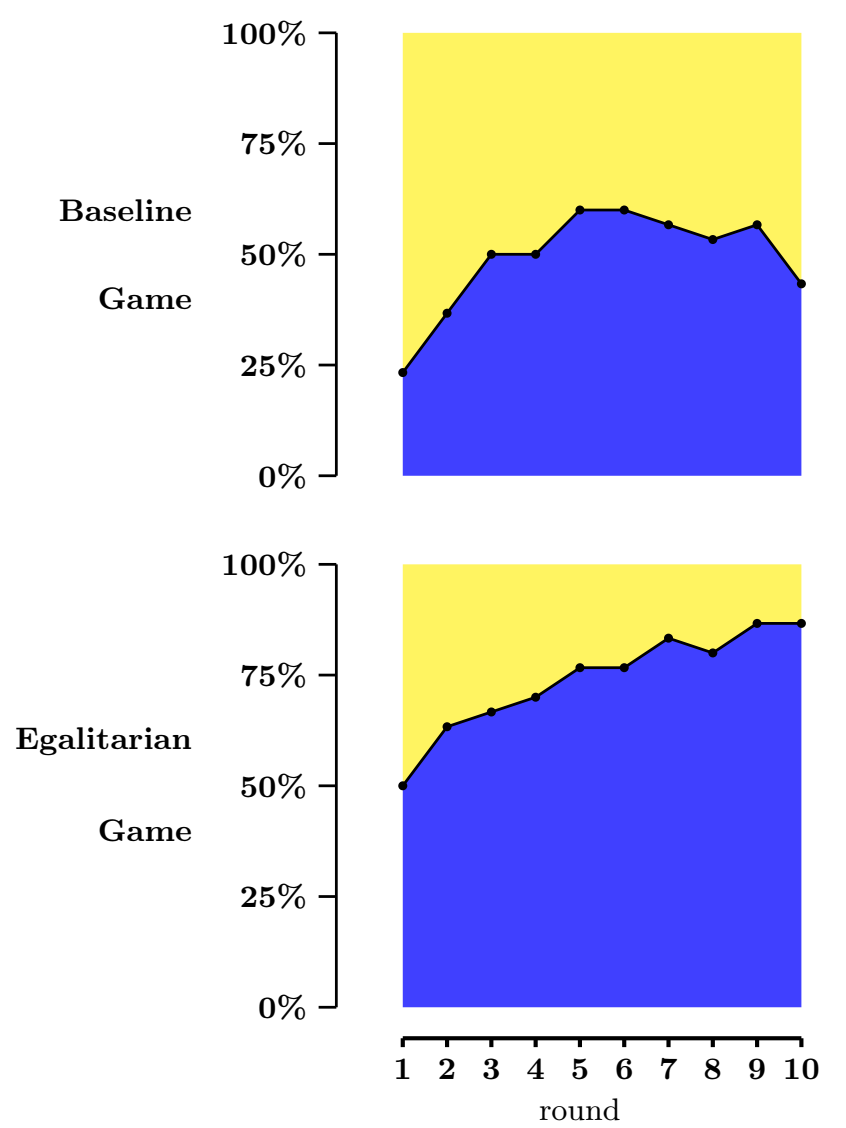

Player B
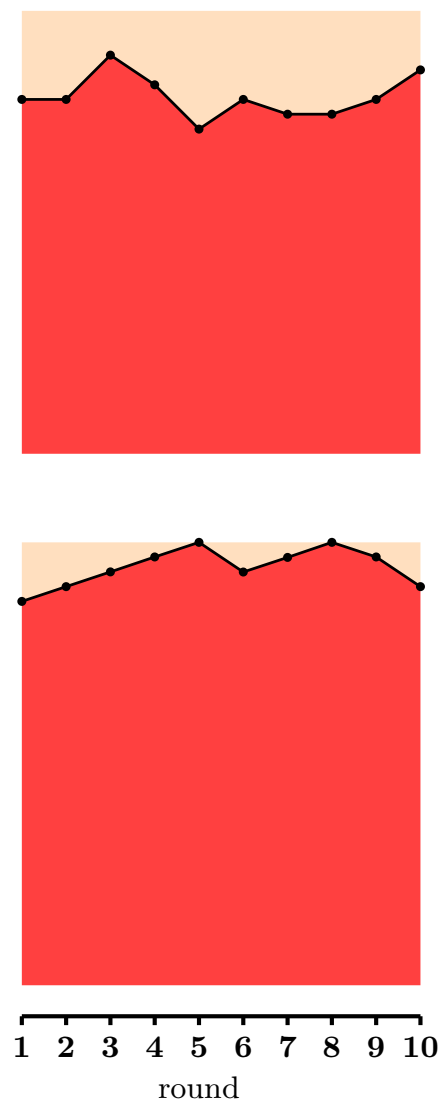

Figure 1: Player behavior when playing with another subject across round by treatment

decision $r$ shifts from $80.7 \%$ in BG to $93.6 \%$ in EG. Both results suggest that subjects do react to the strategic context of the game. Still, the proportion of decisions $L$ is high, in particular in the EG treatment, where almost all decisions from player Bs are payoff maximizing. We now turn to an empirical measure of the extent to which $L$ choices can be explained by strategic uncertainty or by individual bounded rationality.

\subsection{Bounded rationality and strategic uncertainty}

Figure 2 shows the dynamics of the frequencies of $R$ decisions for both games and both treatments. It indicates a substantial increase in the proportion of $R$ decisions when subjects interact with a computer rather than human subjects: in round 1, the percentage of player As who choose $R$ increases from $23 \%$ to $60 \%$ in BG and from $50 \%$ to $84.2 \%$ in EG $9^{9}$ Also, the overall percentage of $R$

\footnotetext{
${ }^{9}$ The null hypothesis that the observed behavior in round 1 is the same for both Human and Robot treatments is rejected with p-value 0.0033 for BG and 0.0035 for EG (Fisher's exact test, two-tailed).
} 
Treatment BG

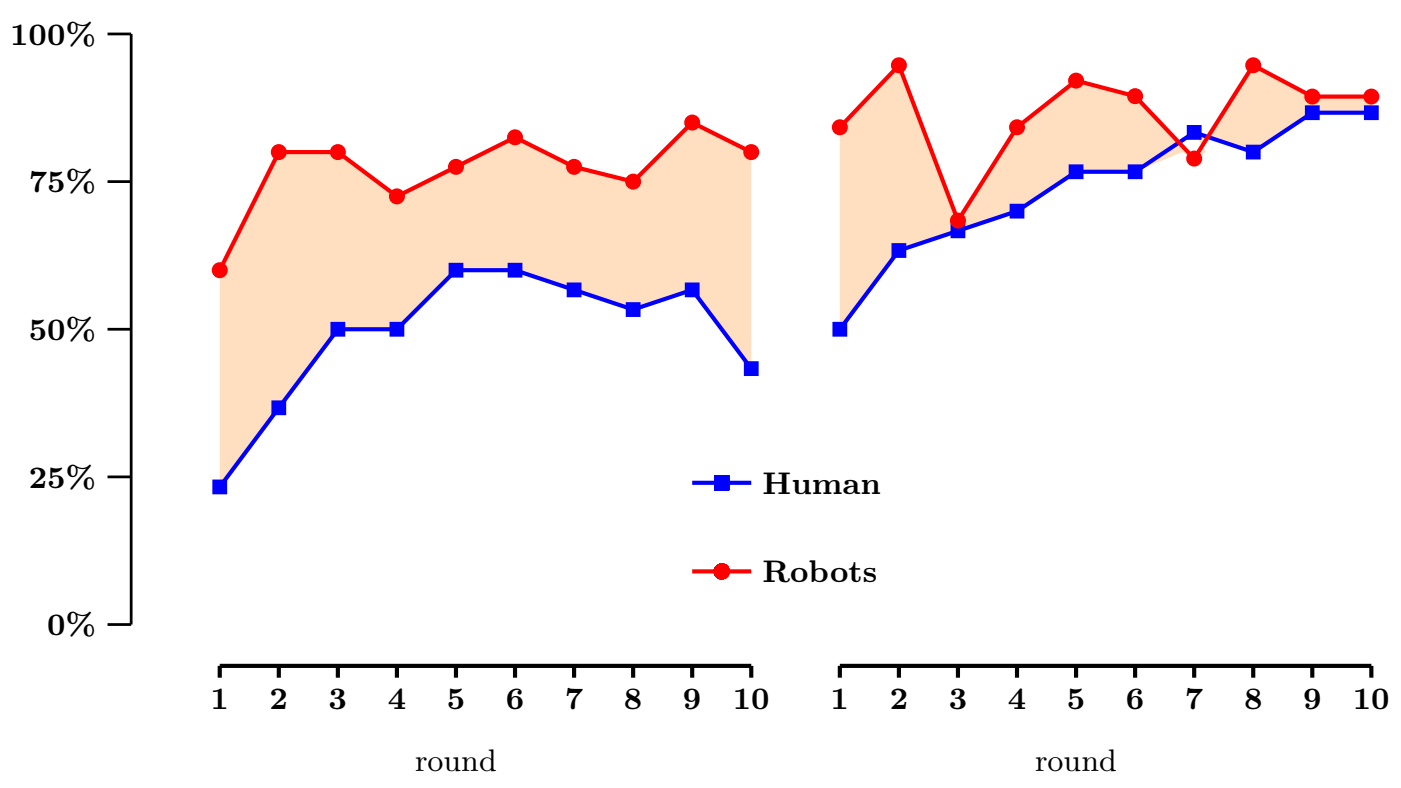

Figure 2: Decision $R$ accross round and treatment

decisions increases from $49 \%$ to $77.0 \%$ in BG, from $77.0 \%$ to $86.6 \%$ in EG. A bootstrap proportion test indicates that this increase in proportion of $R$ choices is significant at a $1 \%$ threshold in BG $(p=.001)$ and at a $10 \%$ threshold in EG $(p=.074)$. It is also clear from Figure 2 that eliminating strategic uncertainty does not lead all player As to select the own-payoff-maximizing choice $R$ in all 10 rounds. On average, we observe that $23 \%$ (13.4\%) of choices are $L$ in BG (EG) when interacting with the computer - even though there is no strategic uncertainty. Such $L$ choices in Robot treatments can only be interpreted in terms of the bounded rationality of subjects.

In Figures 3. a and 3.b, we examine individual data by looking at the Empirical Distribution Function (EDF) of the number of $R$ decisions taken by each individual in BG and in EG. In BG, a larger proportion of subjects take decision $R$ in all rounds when they face a computer rather than another subject - twenty subjects out of $40(50.0 \%)$ choose $R$ ten times when facing a computer whereas only 3 out of $30(10 \%)$ do so when facing another subject. Allowing no mistakes requires a lot from subjects. However, if we relax this requirement by investigating the proportion of subjects choosing $L$ once, we find that the pattern is similar. Thirteen subjects $(32.5 \%)$ choose $R$ strictly less than 9 times when facing a computer, and 23 out of 30 (76.7\%) do so when facing with other subjects. A bootstrap version of the univariate Kolmogorov-Smirnov (KS) test that allows for ties (see, e.g., Abadie, 2002; Sekhon, 2011) shows that the EDF of the individual number of $R$ decisions in Robot treatments first order dominates that in Human treatments $(p<.001)$. The effect of interacting with a computer in EG is of the same nature, although to a lesser extent 

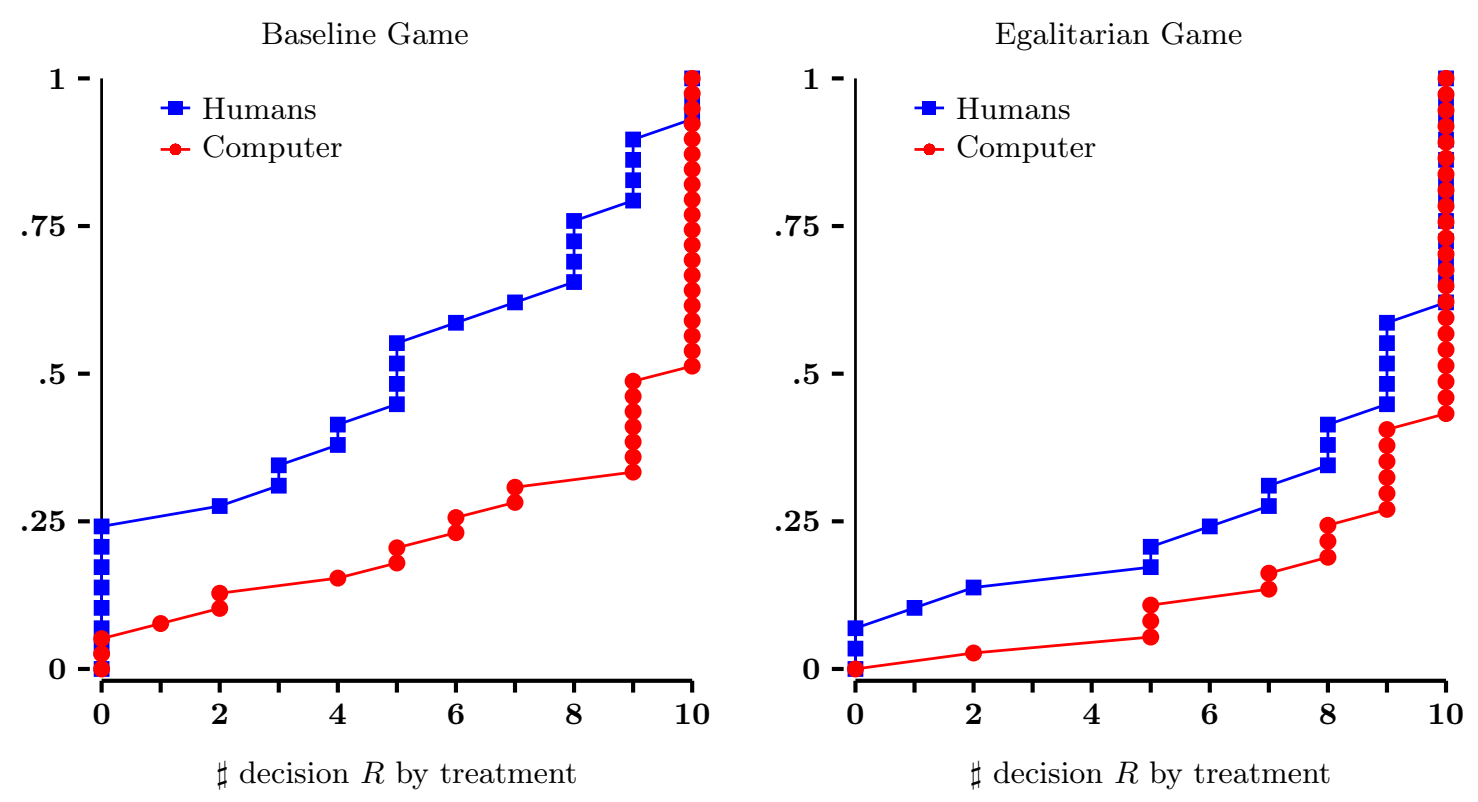

Figure 3: EDF of decision $R$ ratio over round by treatment

than in BG. Now, 28 subjects out of $38(73.7 \%)$ choose $R 9$ or 10 times facing a computer and 16 subjects out of $30(53.3 \%)$ do so facing another subject. The EDF of the individual number of $R$ decisions in Robot treatments also first order dominates the number of $R$ decisions in Human treatments - although not significantly ( $p=.142-$ KS bootstrap test).

Using Robot treatments as a baseline for bounded rationality, we can now estimate to what extent strategic uncertainty explains the choice of the secure option $L$ in Human treatments. As indicated above, we observe that $51 \%$ of choices are $L$ in human BG and $23 \%$ in human EG. Subtracting the proportion of $L$ choices in Robot treatments from the proportion of $L$ choices in Human treatments gives us how much of the $L$ choices can be explained by strategic uncertainty: $28 \%(51.0 \%-23 \%)$ in BG and $9.6 \%(23 \%-13.4 \%)$ in EG. Strategic uncertainty thus accounts for about half of the observed failures to achieve Pareto efficient outcome in these two simple games, whereas bounded rationality does so for the other half.

As a robustness check for effects of learning and individual correlation between rounds, we conduct two simulations, one for each game, that replicate the above calculation. In each simulation, we repeatedly draw subsamples of subjects and their ten choices, with replacement. The proportion of decisions $L$ that are explained by bounded rationality is then computed for each simulation. Means of the empirical distribution of the percentage of decisions explained by bounded rationality in each treatment are very similar to the sample average: $44.7 \%$ in BG (with median $45.7 \%$ ) and $51.3 \%$ (with median 55\%) in EG, thus confirming our sample results. Estimates are, however, less precise in EG than in $\mathrm{BG}$, with simulated confidence intervals of $[27.7 ; 57.9]$ in $\mathrm{BG}$ and $[26.8 ; 75.4]$ in EG. 


\section{Conclusion}

Coordination failures are a widely documented phenomenon, with possibly dramatic economic consequences. While most experimental investigations try to identify the sources of strategic uncertainty underlying such failures, very few of them explore the effect of strategic uncertainty per se. We rely on two examples from a class of very simple two-player two-action games to provide an empirical measure of the proportion of observed coordination failures induced by strategic uncertainty. In this class of games, coordination failures arise when and because one of the two players does not trust the ability of the other to maximize his own monetary payoff. To isolate the effect of strategic uncertainty, we contrast individual decisions depending on whether subjects interact with human beings or with computers whose behavior is known. Our results show that strategic uncertainty accounts for close to half of the observed failures to reach an efficient outcome in the two games we consider. The other half - as measured by the proportion of coordination failures that occur when interacting with preset computers - can only be interpreted as a result of individual bounded rationality; which suggests that some subjects do make non-strategic decisions.

Our results raise interesting questions, which could be explored further. First, our design precludes investigating the reasons behind the observed individual bounded rationality, which might, for example, be due to a lack of focus during the experiment or to some subjects' wish to manipulate the results of the experiment. A better understanding of the reasons behind such boundedly rational choices in strategic contexts, including the advantages of various heuristics as demonstrated in other contexts (Gigerenzer, Todd, and the ABC Research Group, 1999), appears to us a fruitful avenue for future research. Second, more importantly, our results suggest that half of observed coordination failures would not occur if the environment were credibly reassuring about the likely behavior of the opponent. The robot treatment is obviously an artefactual way of implementing such an environment. Finding a similarly reassuring institutional device is next on our agenda.

\section{References}

AbAdie, A. (2002): "Bootstrap Tests for Distributional Treatment Effects in Instrumental Variable Model," Journal of the American Statistical Association, 97(457), 284-292.

AkiYama, E., N. HANAKI, AND R. Ishikawa (2012): "Effect of uncertainty about others' rationality in experimental asset markets: An experimental analysis," Aix-Marseille School of Economics, Working Paper No. 2012-34.

Beard, T. R., and J. Beil, Richard O. (1994): "Do People Rely on the Self-Interested Maximization of Others? An Experimental Test," Management Science, 40(2), 252-262.

Beard, T. R., R. O. J. Beil, and Y. Mataga (2001): "Reliant behavior in the United States and Japan," Economic Inquiry, 39(2), 270-279. 
Cason, T. N., And D. Friedman (1997): "Price Formation in Single Call Markets," Econometrica, 65(2), $311-345$.

Cooper, D. J., AND J. B. VAn Huyck (2003): "Evidence on the equivalence of the strategic and extensive form representation of games," Journal of Economic Theory, 110(2), 290-308.

Costa-Gomes, M. A., And V. P. Crawford (2006): "Cognition and Behavior in Two-Person Guessing Games: An Experimental Study," American Economic Review, 96(5), 1737-1768.

Embrey, M. S., G. R. Fréchette, and S. F. Lehrer (2012): "Bargaining and Reputation: An Experiments on Bargaining in the Presence of Behavioral Types," mimeo, New York University.

Fehr, E., And J.-R. Tyran (2001): "Does Money Illusion Matter?," American Economic Review, 91(5), $1239-1262$.

Gigerenzer, G., P. M. Todd, And the ABC Research Group (1999): Simple Heuristics that Make Us Smart. Oxford University Press, New York, NY.

Goeree, J. K., And C. A. Holt (2001): "Ten Little Treasures of Game Theory and Ten Intuitive Contradictions," American Economic Review, 91(5), 1402-1422.

Greiner, B. (2004): "An Online Recruitment System for Economic Experiments.," in Forschung und wissenschaftliches Rechnen 2003. GWDG Bericht 63, ed. by K. Kremer, and V. Macho, pp. 79-93. Ges. f?r Wiss. Datenverarbeitung, G?ttingen.

Ho, T.-H., C. Camerer, and K. Weigelt (1998): "Iterated Dominance and Iterated Best Response in Experimental "p-Beauty Contests"," American Economic Review, 88(4), 947-969.

Ivanov, A., D. Levin, And M. Niederle (2010): "Can relaxation of beliefs raiontalize the winner's curse?: An experimental study," Econometrica, 78(4), 1435-1452.

Jacquemet, N., R.-V. Joule, S. Luchini, And J. Shogren (2012): "Eliciting Preferences under Oath," Journal of Environmental Economics and Management, Forthcoming.

Jacquemet, N., And A. Zylbersztejn (2011): "What drives failure to maximize payoffs in the lab? A test of the inequality aversion hypothesis?," CES Working Paper, 2011(36).

- (2012): "Learning, words and actions: experimental evidence on coordination-improving information," B.E. Journal of Theoretical Economics, Forthcoming(64).

NAGEL, R. (1995): "Unraveling in Guessing Games: An Experimental Study," American Economics Review, 85(5), 1313-1326.

Polonio, L., And G. Coricelli (2012): "Revealing mental processes in interactive decision-making," Paper presented at 2012 French Experimental Economics Association (ASFEE) annual meeting in Montpellier.

Rosenthal, R. W. (1981): "Games of perfect information, predatory pricing and the chain-store paradox," Journal of Economic Theory, 25(1), 92-100. 
Sekhon, J. (2011): "Multivariate and Propensity Score Matching Software with Automated Balance Optimization," Journal of Statistical Software, 42(7), 1-52.

Selten, R. (1975): "Reexamination of the perfectness concept for equilibrium points in extensive games," International Journal of Game Theory, 4(1), 25-55.

Smith, V. L., G. L. Suchanek, and A. W. Williams (1988): "Bubbles, Crashes. and Endogenous Expectations in Experimental Spot Asset Markets," Econometrica, 56, 1119-1151.

Zeiliger, R. (2000): "A presentation of Regate, Internet based Software for Experimental Economics," http://www.gate.cnrs.fr/ zeiliger/regate/RegateIntro.ppt, GATE. 
Editor, UWA Economics Discussion Papers:

Ernst Juerg Weber

Business School - Economics

University of Western Australia

35 Sterling Hwy

Crawley WA 6009

Australia

Email: ecoadmin@biz.uwa.edu.au

The Economics Discussion Papers are available at:

1980 - 2002: http://ecompapers.biz.uwa.edu.au/paper/PDF\%20of\%20Discussion\%20Papers/

Since 2001: http://ideas.repec.org/s/uwa/wpaper1.html

Since 2004: $\quad$ http://www.business.uwa.edu.au/school/disciplines/economics

\begin{tabular}{|c|c|c|}
\hline \multicolumn{3}{|c|}{$\begin{array}{l}\text { ECONOMICS DISCUSSION PAPERS } \\
2011\end{array}$} \\
\hline $\begin{array}{l}\text { DP } \\
\text { NUMBER }\end{array}$ & AUTHORS & TITLE \\
\hline 11.01 & Robertson, P.E. & $\begin{array}{l}\text { DEEP IMPACT: CHINA AND THE WORLD } \\
\text { ECONOMY }\end{array}$ \\
\hline 11.02 & Kang, C. and Lee, S.H. & $\begin{array}{l}\text { BEING KNOWLEDGEABLE OR SOCIABLE? } \\
\text { DIFFERENCES IN RELATIVE IMPORTANCE OF } \\
\text { COGNITIVE AND NON-COGNITIVE SKILLS }\end{array}$ \\
\hline 11.03 & Turkington, D. & DIFFERENT CONCEPTS OF MATRIX CALCULUS \\
\hline 11.04 & Golley, J. and Tyers, R. & $\begin{array}{l}\text { CONTRASTING GIANTS: DEMOGRAPHIC CHANGE } \\
\text { AND ECONOMIC PERFORMANCE IN CHINA AND } \\
\text { INDIA }\end{array}$ \\
\hline 11.05 & Collins, J., Baer, B. and Weber, E.J. & $\begin{array}{l}\text { ECONOMIC GROWTH AND EVOLUTION: } \\
\text { PARENTAL PREFERENCE FOR QUALITY AND } \\
\text { QUANTITY OF OFFSPRING }\end{array}$ \\
\hline 11.06 & Turkington, D. & $\begin{array}{l}\text { ON THE DIFFERENTIATION OF THE LOG } \\
\text { LIKELIHOOD FUNCTION USING MATRIX } \\
\text { CALCULUS }\end{array}$ \\
\hline 11.07 & Groenewold, N. and Paterson, J.E.H. & $\begin{array}{l}\text { STOCK PRICES AND EXCHANGE RATES IN } \\
\text { AUSTRALIA: ARE COMMODITY PRICES THE } \\
\text { MISSING LINK? }\end{array}$ \\
\hline 11.08 & Chen, A. and Groenewold, N. & $\begin{array}{l}\text { REDUCING REGIONAL DISPARITIES IN CHINA: IS } \\
\text { INVESTMENT ALLOCATION POLICY EFFECTIVE? }\end{array}$ \\
\hline 11.09 & Williams, A., Birch, E. and Hancock, P. & $\begin{array}{l}\text { THE IMPACT OF ON-LINE LECTURE RECORDINGS } \\
\text { ON STUDENT PERFORMANCE }\end{array}$ \\
\hline 11.10 & Pawley, J. and Weber, E.J. & $\begin{array}{l}\text { INVESTMENT AND TECHNICAL PROGRESS IN THE } \\
\text { G7 COUNTRIES AND AUSTRALIA }\end{array}$ \\
\hline 11.11 & Tyers, R. & $\begin{array}{l}\text { AN ELEMENTAL MACROECONOMIC MODEL FOR } \\
\text { APPLIED ANALYSIS AT UNDERGRADUATE LEVEL }\end{array}$ \\
\hline 11.12 & Clements, K.W. and Gao, G. & QUALITY, QUANTITY, SPENDING AND PRICES \\
\hline 11.13 & Tyers, R. and Zhang, Y. & $\begin{array}{l}\text { JAPAN'S ECONOMIC RECOVERY: INSIGHTS FROM } \\
\text { MULTI-REGION DYNAMICS }\end{array}$ \\
\hline
\end{tabular}




\begin{tabular}{|c|c|c|}
\hline 11.14 & McLure, M. & A. C. PIGOU'S REJECTION OF PARETO'S LAW \\
\hline 11.15 & Kristoffersen, I. & $\begin{array}{l}\text { THE SUBJECTIVE WELLBEING SCALE: HOW } \\
\text { REASONABLE IS THE CARDINALITY } \\
\text { ASSUMPTION? }\end{array}$ \\
\hline 11.16 & Clements, K.W., Izan, H.Y. and Lan, Y. & VOLATILITY AND STOCK PRICE INDEXES \\
\hline 11.17 & Parkinson, M. & $\begin{array}{l}\text { SHANN MEMORIAL LECTURE 2011: SUSTAINABLE } \\
\text { WELLBEING - AN ECONOMIC FUTURE FOR } \\
\text { AUSTRALIA }\end{array}$ \\
\hline 11.18 & Chen, A. and Groenewold, N. & $\begin{array}{l}\text { THE NATIONAL AND REGIONAL EFFECTS OF } \\
\text { FISCAL DECENTRALISATION IN CHINA }\end{array}$ \\
\hline 11.19 & Tyers, R. and Corbett, J. & $\begin{array}{l}\text { JAPAN'S ECONOMIC SLOWDOWN AND ITS } \\
\text { GLOBAL IMPLICATIONS: A REVIEW OF THE } \\
\text { ECONOMIC MODELLING }\end{array}$ \\
\hline 11.20 & Wu, Y. & $\begin{array}{l}\text { GAS MARKET INTEGRATION: GLOBAL TRENDS } \\
\text { AND IMPLICATIONS FOR THE EAS REGION }\end{array}$ \\
\hline 11.21 & Fu, D., Wu, Y. and Tang, Y. & $\begin{array}{l}\text { DOES INNOVATION MATTER FOR CHINESE HIGH- } \\
\text { TECH EXPORTS? A FIRM-LEVEL ANALYSIS }\end{array}$ \\
\hline 11.22 & $\mathrm{Fu}, \mathrm{D}$. and $\mathrm{Wu}, \mathrm{Y}$. & $\begin{array}{l}\text { EXPORT WAGE PREMIUM IN CHINA'S } \\
\text { MANUFACTURING SECTOR: A FIRM LEVEL } \\
\text { ANALYSIS }\end{array}$ \\
\hline 11.23 & Li, B. and Zhang, J. & $\begin{array}{l}\text { SUBSIDIES IN AN ECONOMY WITH ENDOGENOUS } \\
\text { CYCLES OVER NEOCLASSICAL INVESTMENT AND } \\
\text { NEO-SCHUMPETERIAN INNOVATION REGIMES }\end{array}$ \\
\hline 11.24 & Krey, B., Widmer, P.K. and Zweifel, P. & $\begin{array}{l}\text { EFFICIENT PROVISION OF ELECTRICITY FOR THE } \\
\text { UNITED STATES AND SWITZERLAND }\end{array}$ \\
\hline 11.25 & $\mathrm{Wu}, \mathrm{Y}$. & $\begin{array}{l}\text { ENERGY INTENSITY AND ITS DETERMINANTS IN } \\
\text { CHINA'S REGIONAL ECONOMIES }\end{array}$ \\
\hline
\end{tabular}




\section{ECONOMICS DISCUSSION PAPERS}

2012

\begin{tabular}{|c|c|c|}
\hline $\begin{array}{l}\text { DP } \\
\text { NUMBER }\end{array}$ & AUTHORS & TITLE \\
\hline 12.01 & $\begin{array}{l}\text { Clements, K.W., Gao, G., and } \\
\text { Simpson, T. }\end{array}$ & $\begin{array}{l}\text { DISPARITIES IN INCOMES AND PRICES } \\
\text { INTERNATIONALLY }\end{array}$ \\
\hline 12.02 & Tyers, R. & $\begin{array}{l}\text { THE RISE AND ROBUSTNESS OF ECONOMIC FREEDOM } \\
\text { IN CHINA }\end{array}$ \\
\hline 12.03 & Golley, J. and Tyers, R. & $\begin{array}{l}\text { DEMOGRAPHIC DIVIDENDS, DEPENDENCIES AND } \\
\text { ECONOMIC GROWTH IN CHINA AND INDIA }\end{array}$ \\
\hline 12.04 & Tyers, R. & LOOKING INWARD FOR GROWTH \\
\hline 12.05 & Knight, K. and McLure, M. & THE ELUSIVE ARTHUR PIGOU \\
\hline 12.06 & McLure, M. & $\begin{array}{l}\text { ONE HUNDRED YEARS FROM TODAY: A. C. PIGOU'S } \\
\text { WEALTH AND WELFARE }\end{array}$ \\
\hline 12.07 & Khuu, A. and Weber, E.J. & HOW AUSTRALIAN FARMERS DEAL WITH RISK \\
\hline 12.08 & Chen, M. and Clements, K.W. & PATTERNS IN WORLD METALS PRICES \\
\hline 12.09 & Clements, K.W. & UWA ECONOMICS HONOURS \\
\hline 12.10 & Golley, J. and Tyers, R. & $\begin{array}{l}\text { CHINA'S GENDER IMBALANCE AND ITS ECONOMIC } \\
\text { PERFORMANCE }\end{array}$ \\
\hline 12.11 & Weber, E.J. & $\begin{array}{l}\text { AUSTRALIAN FISCAL POLICY IN THE AFTERMATH OF } \\
\text { THE GLOBAL FINANCIAL CRISIS }\end{array}$ \\
\hline 12.12 & Hartley, P.R. and Medlock III, K.B. & $\begin{array}{l}\text { CHANGES IN THE OPERATIONAL EFFICIENCY OF } \\
\text { NATIONAL OIL COMPANIES }\end{array}$ \\
\hline 12.13 & Li, L. & $\begin{array}{l}\text { HOW MUCH ARE RESOURCE PROJECTS WORTH? A } \\
\text { CAPITAL MARKET PERSPECTIVE }\end{array}$ \\
\hline 12.14 & Chen, A. and Groenewold, N. & $\begin{array}{l}\text { THE REGIONAL ECONOMIC EFFECTS OF A } \\
\text { REDUCTION IN CARBON EMISSIONS AND AN } \\
\text { EVALUATION OF OFFSETTING POLICIES IN CHINA }\end{array}$ \\
\hline 12.15 & Collins, J., Baer, B. and Weber, E.J. & $\begin{array}{l}\text { SEXUAL SELECTION, CONSPICUOUS CONSUMPTION } \\
\text { AND ECONOMIC GROWTH }\end{array}$ \\
\hline 12.16 & Wu, Y. & TRENDS AND PROSPECTS IN CHINA'S R\&D SECTOR \\
\hline 12.17 & Cheong, T.S. and Wu, Y. & $\begin{array}{l}\text { INTRA-PROVINCIAL INEQUALITY IN CHINA: AN } \\
\text { ANALYSIS OF COUNTY-LEVEL DATA }\end{array}$ \\
\hline 12.18 & Cheong, T.S. & THE PATTERNS OF REGIONAL INEQUALITY IN CHINA \\
\hline 12.19 & Wu, Y. & $\begin{array}{l}\text { ELECTRICITY MARKET INTEGRATION: GLOBAL } \\
\text { TRENDS AND IMPLICATIONS FOR THE EAS REGION }\end{array}$ \\
\hline 12.20 & Knight, K. & $\begin{array}{l}\text { EXEGESIS OF DIGITAL TEXT FROM THE HISTORY OF } \\
\text { ECONOMIC THOUGHT: A COMPARATIVE } \\
\text { EXPLORATORY TEST }\end{array}$ \\
\hline 12.21 & Chatterjee, I. & $\begin{array}{l}\text { COSTLY REPORTING, EX-POST MONITORING, AND } \\
\text { COMMERCIAL PIRACY: A GAME THEORETIC } \\
\text { ANALYSIS }\end{array}$ \\
\hline 12.22 & Pen, S.E. & QUALITY-CONSTANT ILLICIT DRUG PRICES \\
\hline 12.23 & Cheong, T.S. and Wu, Y. & $\begin{array}{l}\text { REGIONAL DISPARITY, TRANSITIONAL DYNAMICS } \\
\text { AND CONVERGENCE IN CHINA }\end{array}$ \\
\hline
\end{tabular}




\begin{tabular}{|l|l|l|}
\hline 12.24 & Ezzati, P. & $\begin{array}{l}\text { FINANCIAL MARKETS INTEGRATION OF IRAN } \\
\text { WITHIN THE MIDDLE EAST AND WITH THE REST OF } \\
\text { THE WORLD }\end{array}$ \\
\hline 12.25 & Kwan, F., Wu, Y. and Zhuo, S. & $\begin{array}{l}\text { RE-EXAMINATION OF THE SURPLUS AGRICULTURAL } \\
\text { LABOUR IN CHINA }\end{array}$ \\
\hline 12.26 & Wu. Y. & R\&D BEHAVIOUR IN CHINESE FIRMS \\
\hline 12.27 & Tang, S.H.K. and Yung, L.C.W. & $\begin{array}{l}\text { MAIDS OR MENTORS? THE EFFECTS OF LIVE-IN } \\
\text { FOREIGN DOMESTIC WORKERS ON SCHOOL } \\
\text { CHILDREN'S EDUCATIONAL ACHIEVEMENT IN HONG } \\
\text { KONG }\end{array}$ \\
\hline 12.28 & Groenewold, $\mathrm{N}$. & $\begin{array}{l}\text { AUSTRALIA AND THE GFC: SAVED BY ASTUTE } \\
\text { FISCAL POLICY? }\end{array}$ \\
\hline
\end{tabular}

\section{ECONOMICS DISCUSSION PAPERS \\ 2013}

\begin{tabular}{|c|c|c|}
\hline $\begin{array}{l}\text { DP } \\
\text { NUMBER }\end{array}$ & AUTHORS & TITLE \\
\hline 13.01 & $\begin{array}{l}\text { Chen, M., Clements, K.W. and } \\
\text { Gao, G. }\end{array}$ & THREE FACTS ABOUT WORLD METAL PRICES \\
\hline 13.02 & Collins, J. and Richards, O. & $\begin{array}{l}\text { EVOLUTION, FERTILITY AND THE AGEING } \\
\text { POPULATION }\end{array}$ \\
\hline 13.03 & $\begin{array}{l}\text { Clements, K., Genberg, H., } \\
\text { Harberger, A., Lothian, J., } \\
\text { Mundell, R., Sonnenschein, H. and } \\
\text { Tolley, G. }\end{array}$ & LARRY SJAASTAD, 1934-2012 \\
\hline 13.04 & Robitaille, M.C. and Chatterjee, I. & MOTHERS-IN-LAW AND SON PREFERENCE IN INDIA \\
\hline 13.05 & Clements, K.W. and Izan, I.H.Y. & $\begin{array}{l}\text { REPORT ON THE } 25^{\mathrm{TH}} \text { PHD CONFERENCE IN } \\
\text { ECONOMICS AND BUSINESS }\end{array}$ \\
\hline 13.06 & Walker, A. and Tyers, R. & QUANTIFYING AUSTRALIA’S “THREE SPEED” BOOM \\
\hline 13.07 & Yu, F. and $\mathrm{Wu}, \mathrm{Y}$. & PATENT EXAMINATION AND DISGUISED PROTECTION \\
\hline 13.08 & $\mathrm{Yu}, \mathrm{F}$. and $\mathrm{Wu}, \mathrm{Y}$. & $\begin{array}{l}\text { PATENT CITATIONS AND KNOWLEDGE SPILLOVERS: } \\
\text { AN ANALYSIS OF CHINESE PATENTS REGISTER IN } \\
\text { THE US }\end{array}$ \\
\hline 13.09 & Chatterjee, I. and Saha, B. & BARGAINING DELEGATION IN MONOPOLY \\
\hline 13.10 & Cheong, T.S. and Wu, Y. & $\begin{array}{l}\text { GLOBALIZATION AND REGIONAL INEQUALITY IN } \\
\text { CHINA }\end{array}$ \\
\hline 13.11 & Cheong, T.S. and Wu, Y. & INEQUALITY AND CRIME RATES IN CHINA \\
\hline 13.12 & Robertson, P.E. and Ye, L. & ON THE EXISTENCE OF A MIDDLE INCOME TRAP \\
\hline 13.13 & Robertson, P.E. & THE GLOBAL IMPACT OF CHINA’S GROWTH \\
\hline 13.14 & $\begin{array}{l}\text { Hanaki, N., Jacquemet, N., } \\
\text { Luchini, S., and Zylbersztejn, A. }\end{array}$ & $\begin{array}{l}\text { BOUNDED RATIONALITY AND STRATEGIC } \\
\text { UNCERTAINTY IN A SIMPLE DOMINANCE SOLVABLE } \\
\text { GAME }\end{array}$ \\
\hline
\end{tabular}

